\title{
Museologia social: apontamentos históricos e conceituais
}

\author{
Atila Bezerra Tolentino ${ }^{1}$
}

\section{Resumo:}

O presente artigo pretende apresentar uma breve trajetória histórica e conceitual sobre o campo da museologia social e da Sociomuseologia. A discussão procura identificar como as reflexões e os debates na área impactaram no fazer museológico, com a criação de museus comunitários e a ressignificação das narrativas e práticas museológicas dos museus já existentes, como também nas reflexões teóricas que se travavam no campo da museologia. Ainda se propõe a problematizar as interfaces e diferenças entre o

${ }^{1}$ Graduado em Letras Português pela Universidade de Brasília - UnB (1997), com especialização em políticas públicas e gestão governamental pela Escola Nacional de Administração Pública (1999) e em gestão de políticas públicas de cultura pela UnB (2008). Mestre em Sociologia na Universidade Federal da Paraíba - UFPB. É da carreira de Especialista em Políticas Públicas e Gestão Governamental do Ministério do Planejamento, Orçamento e Gestão, com atuação no Instituto do Patrimônio Histórico e Artístico Nacional do Ministério da Cultura. Coordena as atividades da Casa do Patrimônio da Paraíba, programa de educação patrimonial vinculado à Superintendência do Iphan na Paraíba. Participa da coordenação da Rede de Educadores em Museus da Paraíba. Tem experiência na área de museologia e patrimônio, atuando principalmente com os seguintes temas: políticas públicas de cultura, museologia, patrimônio cultural e educação patrimonial.

Instituto do Patrimônio Histórico e Artístico Nacional atilabt@gmail.com 
que vem a ser museologia social e Sociomuseologia, bem como os dilemas e conflitos no campo acadêmico a que está sujeita essa linha de reflexão.

Palavras-chave: museologia social, Sociomuseologia, museus comunitários

\begin{abstract}
:
This article aims to present a brief historical and conceptual trajectory on the field of social museology and Sociomuseology. The discussion seeks to identify how the discussions and debates in this area affected in the way how museums work, with the creation of community museums and the reframing of the narrative and museological practices of existing museums. As well, it aims to identify how it also affected in the theoretical reflections in the field of museology. It still intends to discuss the connections and differences between what is social museology and Sociomuseology, as so the dilemmas and conflicts in this academic field.
\end{abstract}

Keywords: social museology, Sociomuseology, community museums

O modelo de museus a que estamos habituados e mais conhecemos na atualidade é ainda aquele modelo atrelado à formação dos Estados-nação e, paralelamente, à preservação de monumentos representativos da herança cultural das nações. A preservação de tais monumentos, na explicação de Cecília Londres (2005), data dos anos finais do século XVII, quando o Estado, na Europa, passa a assumir a proteção legal de determinados bens aos quais foi atribuída a capacidade de simbolizarem a nação. Assim, as noções modernas de monumento histórico, patrimônio e preservação começam a ser elaboradas a partir do momento em que surge a ideia de estudar e conservar um edifício pela razão de que é um testemunho da história ou considerado uma obra de arte. A tarefa de seleção entre conservar ou destruir monumentos cabia a determinados agentes, legitimando processos de atribuição de valores segundo determinados critérios. Nesse processo, manifestam-se os 
conflitos de interesse na prática preservacionista de bens culturais em nome do interesse público.

Londres ainda expõe que o sentimento de piedade religiosa e de devoção às relíquias, na Europa, constituiu a origem do sentimento de apego aos bens simbólicos. No século $\mathrm{XV}$ ocorreram as primeiras medidas de preservação, mas durante os três séculos seguintes a preservação de monumentos se manifestava basicamente em iniciativas isoladas. Prédios antigos (vinculados a culturas pagãs) eram ressemantizados e retraduzidos em termos cristãos. Muitos eram reutilizados ou tinham seus elementos aproveitados em outras construções. Foi a ideia de nação que veio garantir o estatuto ideológico à constituição dos patrimônios históricos e artísticos e coube ao Estado nacional assegurar a sua preservação. A noção de monumento, no seu sentido moderno, ou seja, formulada enquanto monumento histórico e artístico, é que fez com que a noção de patrimônio se convertesse em uma categoria socialmente definida, regulamentada e delimitada. Foi preciso que surgissem ameaças concretas de perda de monumentos (já então valorizados como expressões históricas e artísticas), como o vandalismo da Reforma e o da Revolução Francesa, além da mística do culto à nação, para que a preservação dos monumentos se tornasse um tema de interesse público e, podemos acrescentar, a prática preservacionista também por meio dos museus.

No Brasil, a prática preservacionista, seguindo a tendência europeia, está intimamente ligada à ideia de formação e afirmação do Estado-nação, bem como ao surgimento dos museus e de outras instituições de memória. Ainda como Reino Unido de Portugal, em 1818, ou seja, dez anos após a chegada da família real ao Brasil, é criado o Museu Real (hoje Museu Nacional, que funciona na Quinta da Boa Vista, no Rio de Janeiro). No início da República, segundo Guarnieri (2010), a tendência é o surgimento de museus provinciais (depois 
estaduais). A busca de uma identidade nacional genuinamente brasileira, no entanto, é tomada somente com a rajada nacionalista a partir de 1922, cujo expoente é a Semana de Arte Moderna. É nesse contexto que se cria, em 1922, o Museu Histórico Nacional - MHN, idealizado por Gustavo Barroso, figura de destaque na luta pela preservação dos ícones e bens representativos da identidade nacional brasileira. Dentro do MHN, instalam-se o primeiro Curso de Museologia no Brasil, em 1932 (hoje vinculado à Universidade Federal do Estado do Rio de Janeiro - Unirio), e a Inspetoria dos Monumentos Nacionais, em 1934, esta norteada por uma perspectiva tradicionalista e patriótica. Portanto, é no âmbito dos museus, como afirma Londres (2005), que surgiram as primeiras iniciativas na área de preservação dos monumentos históricos no Brasil.

Durante o momento de centralização do poder, no governo de Getúlio Vargas, é criado, por meio do Decreto-Lei no 25, de 30 de novembro de 1937, o Serviço do Patrimônio Histórico e Artístico Nacional - Sphan (hoje Instituto do Patrimônio Histórico e Artístico Nacional - Iphan), que tem por finalidade determinar, organizar, conservar, defender e propagar o patrimônio histórico e artístico nacional. Instituição ícone da época, o Sphan foi resultado de anteprojeto elaborado por Mário de Andrade, a pedido do então Ministro de Educação e Saúde, Gustavo Capanema. Muitos são os autores (LONDRES, 2005; CHAGAS, 2006; SILVA, 2007) que apontam o caráter extremamente inovador desse anteprojeto, em que está patente o resultado dos estudos empreendidos pelo intelectual, pesquisador e poeta, sempre preocupado com a identificação de uma cultura nacional, antecipando, inclusive, os preceitos da Carta de Veneza de 1964.

Especificamente no campo dos museus, o anteprojeto de Mário de Andrade previa a incorporação de quatro museus nacionais ao Sphan, que cuidariam, cada um, 
das seguintes áreas: i) arqueologia e etnografia, ii) história, iii) belas-artes e iv) artes aplicadas e tecnologia industrial. Esses museus deveriam dar conta das oito categorias em que Mário de Andrade subdividiu o patrimônio artístico nacional: a) arte arqueológica, b) arte ameríndia, c) arte popular, d) arte histórica, e) arte erudita nacional, f) arte erudita estrangeira, g) artes plásticas nacionais e $\mathrm{h}$ ) artes plásticas estrangeiras (CHAGAS, 2005).

Desses museus, dois já estavam funcionando: o Museu Nacional da Quinta da Boa Vista e o Museu Histórico Nacional. A Escola Nacional de Belas Artes, por sua vez, faria o papel do Museu Nacional de Belas Artes. E o Museu de Artes Aplicadas e Tecnologia Industrial seria uma instituição inteiramente nova. Podemos observar, nesse sentido, que o anteprojeto proposto por Mário de Andrade previa uma espécie de sistema para o setor museológico no país, com os quatro museus nacionais à frente das quatro áreas do patrimônio pensadas pelo poeta. Tal proposta, entretanto, não foi recepcionada quando da instituição do Decreto-lei no 25/37, o que contribuiu para distanciar o anteprojeto de Mário de Andrade do instrumento legal oficializado. As tentativas de implantação de políticas públicas voltadas para o setor museológico no país e de criação de um sistema nacional de museus só retornariam ao debate a partir da década de 1970 (TOLENTINO, 2011). Em pleno regime militar, o então Instituto Joaquim Nabuco de Pesquisas Sociais (hoje Fundação Joaquim Nabuco) promoveu, no período de 22 a 26 de outubro de 1975, o Encontro Nacional de Dirigentes de Museus, do qual participaram representantes e diretores de museus de todo o país e renomados intelectuais da época, como o sociólogo e antropólogo Gilberto Freyre e Aloísio Magalhães, então diretor do Centro Nacional de Referências Culturais. 
Durante todo esse período, o que se verifica é que a criação e configuração dos museus estavam basicamente adstritas aos aparelhos ideológicos do Estado, bem como às classes e segmentos dominantes. Foi um fenômeno puramente colonialista, como observa Hugues de Varine: "Foram os países europeus que impuseram aos não europeus seu método de análise do fenômeno e patrimônio culturais; obrigaram as elites e os povos destes países a ver sua própria cultura com olhos europeus" (VARINE apud CHAGAS \& GOUVEIA, 2014, p. 10). Se durante o Brasil Império até meados do século $X X$, o conceito de nação e $O$ conhecimento científico é que agenciaram o surgimento dos museus no país, a partir da segunda metade do século $X X$ a figura da instituição museológica terá quebrada a sua posição cômoda, e seu papel e função perante a sociedade passam a ser questionados. Atrelada a uma prática museológica, nesse contexto também surgem os estudos no campo da museologia, defendida como ciência por alguns e como técnica por outros. Da mesma forma que a instituição museológica, os estudos no campo da museologia também passaram por uma dinâmica de transformação. Em meio aos novos pensamentos que permeavam os anseios sociais no segundo pós-guerra e intensificados pelas ideias revolucionárias inerentes à década de 1960, afloram os debates sobre uma museologia social. Necessário se faz, portanto, problematizar sobre o que se chama de museologia social e Sociomuseologia. Essa discussão se faz importante para compreendermos como se deu o surgimento dos museus comunitários e inúmeras outras terminologias a eles inerentes.

Museologia social e Sociomuseologia: interfaces e diferenças

"Por uma sociologia dos museus" é o título do artigo publicado pela socióloga Myrian Sepúlveda dos Santos 
(2014) nos Cadernos do Centro de Memória do Oeste Catarinense - Ceom. O título chama a atenção porque de antemão já parece advogar a necessidade de refletir o campo dos museus e da museologia com base nos fundamentos do pensamento sociológico. Em sua reflexão, a autora inicia esclarecendo que é bem mais antigo o interesse dos antropólogos pelos museus do que o apresentado pelos sociólogos.

Entre os autores clássicos da Sociologia, explica que Marx, Weber e Durkheim não deram atenção às atividades consideradas de entretenimento ou lazer. Marx centrou-se na luta de classes e seu foco de análise eram as relações sociais de produção. Os museus também não estavam presentes nas principais formulações dos paradigmas da ação e reprodução social de Weber e Durkheim, pois foram priorizados os estudos de práticas culturais, como crenças religiosas associadas a representações coletivas construídas e partilhadas pela sociedade.

Somente a partir da década de 1970, influenciados pelas abordagens que se voltam para as interações individuais deixadas pela Escola de Chicago e pelo sociólogo alemão Georg Simmel, e livres do desejo inicial da Sociologia em se alcançar a objetividade científica em suas análises, é que os sociólogos se ativeram ao campo dos museus, dentro dos estudos culturais, compreendidos como lócus de conflitos de poder simbólico. Em suas palavras:

É justamente esta corrente da sociologia, bem próxima dos estudos culturais pós-coloniais, que tomou para si o estudo dos museus, não só a partir de seus valores constituídos, mas também como lugares de poder.

(...) 
Todas essas novas abordagens modificaram significativamente a forma pela qual os museus eram analisados. O uso das diversas narrativas expostas nos museus passou a ser compreendido a partir de estruturas de poder, processos de institucionalização e de sua relação com contextos políticos e econômicos mais amplos. O museu deixou de ser pensado meramente enquanto instituição que se voltava para a preservação de objetos de arte ou relíquias do passado, passando a integrar o rol de instituições responsáveis por formulações garantidoras da estabilidade política dos estados nacionais em suas diversas fases (SANTOS, 2014, p. 50).

Myrian Sepúlveda segue a sua discussão fazendo a relação entre a Sociologia e o campo dos museus, abordando diferentes autores e escolas sociológicas, demonstrando como a Museologia se inseriu nos estudos culturais e como os museus foram analisados, nesse contexto, como parte de um processo de transformação de sociedades modernas, cujas narrativas estão associadas ao poder e dominação e, ao mesmo tempo, como possíveis práticas sociais que incorporam segmentos da população anteriormente excluídos.

Ao pensar os museus dentro do campo da Sociologia, é importante também compreender o que permeia essa renovação no pensamento no campo dos museus, que se deu entre os anos 1960 e 1970, e seus impactos nas práticas museológicas e na "imaginação museal" (CHAGAS, 2009) brasileiras, hoje recorrentemente chamada de "museologia social" ou "Sociomuseologia". Primeiramente, cumpre esclarecer que esses dois termos são comumente utilizados de forma indistinta e até mesmo como sinônimos, como Mário Chagas e Inês Gouveia fazem questão de enfatizar no texto de apresentação do Caderno do Ceom no 41, intitulado Museologia Social, que traz uma coletânea de artigos, documentos e 
entrevistas que abordam essa temática: "Para todos os efeitos, a presente publicação considera a museologia social e a sociomuseologia como sinônimos, a diferença ainda não investigada em profundidade, estaria na ênfase e no ponto de partida" (CHAGAS; GOUVEIA, 2014, p. 16).

Sem pretender esgotar o assunto, essa indistinção precisa realmente ser problematizada. Gustave Flaubert costumava dizer que não existem sinônimos perfeitos, ou seja, é sempre preciso encontrar, para designar as coisas, a palavra pura, le mot juste. Chagas e Gouveia, ao discorrem sobre a conceituação do que vem a ser museologia social ou Sociomuseologia, apresentam documentos e citações em que os termos são tratados indistintamente. O primeiro deles é a Ordem de Serviço no 27, de 26 de maio de 1993, do Instituto Superior de Matemática e Gestão (que deu origem à Universidade Lusófona de Humanidades e Tecnologia), de Lisboa, Portugal, que seria o primeiro documento a registrar, oficialmente, as expressões museologia social e Sociomuseologia. Esse documento tinha como finalidade criar um Centro de Estudos de Sociomuseologia, a partir do curso de Especialização em Museologia Social encabeçado por Mário Moutinho. O documento ressaltava que esse curso foi responsável por uma contribuição decisiva para a consolidação de "novas vidências e vivências museológicas, que se procuraram sintetizar na designação terminológica e epistemologicamente inovadora 'Museologia Social' ou 'Sociomuseologia'" (apud CHAGAS \& GOUVEIA, 2014, p. 14).

Em seguida, trazem uma citação do próprio Mario Moutinho, em breve ensaio intitulado "Sobre o conceito de Museologia Social", datado de 1993, no qual expõe que "o conceito de Museologia Social traduz uma parte considerável do esforço de adequação das estruturas museológicas aos condicionalismos da sociedade contemporânea" (MOUTINHO, apud CHAGAS \& GOUVEIA, 2014, p. 15). Nesse ensaio, Moutinho se reporta à fala do diretor Geral da Unesco, Frederic Mayor, na 
abertura da XV Conferência Geral do Icom, bem como a documentos internacionais de encontros na área da museologia, que abordam um novo modo de pensar a museologia, que denuncia uma museologia aristocrática e abarca um fazer museal mais comprometido com os problemas sociais das comunidades a que serve. Sintetiza que "a abertura do museu ao meio e a sua relação orgânica com o contexto social que lhe dá vida tem provocado a necessidade de elaborar e esclarecer relações, noções e conceitos que podem dar conta deste processo" (MOUTINHO, 1993, p. 8).

Para fazer um paralelo com esse texto, é interessante analisar outro ensaio de Mário Moutinho, mais recente, intitulado "Definição evolutiva de Sociomuseologia: proposta de reflexão", apresentado por conta do XIII Atelier Internacional do Movimento Internacional para uma Nova Museologia - Minom, em 2007, na cidade de Lisboa. Nesse texto, Moutinho procura estabelecer o que vem a ser Sociomuseologia e, a exemplo do anterior, toma como base documentos internacionais na área da museologia e as reflexões que se seguiram ao longo do tempo. Inicia afirmando que "a Sociomuseologia traduz uma parte considerável do esforço de adequação das estruturas museológicas aos condicionalismos da sociedade contemporânea" (MOUTINHO, 2014, p. 423), portanto, utiliza os mesmos termos do ensaio de 1993, quando denominava "museologia social". Mas diferentemente do texto anterior, Moutinho trata a Sociomuseologia como uma área disciplinar, pautada na interdisciplinaridade:

A Sociomuseologia constitui-se, assim, como uma área disciplinar de ensino, investigação e atuação que privilegia a articulação da museologia, em particular, com as áreas do conhecimento das Ciências Humanas, dos Estudos do Desenvolvimento, da Ciência de Serviços e do Planejamento do Território.

(...) 
O que caracteriza a Sociomuseologia não é propriamente a natureza dos seus pressupostos e dos seus objetivos, como acontece em outras áreas do conhecimento, mas a interdisciplinaridade com que apela a áreas do conhecimento perfeitamente consolidadas e as relaciona com a Museologia propriamente dita. (MOUTINHO, 2014, p. 423).

Moutinho ainda faz questão de reforçar que a visão restritiva da museologia como técnica de trabalho orientada para as coleções tem sido substituída por uma nova compreensão e práticas museológicas orientadas para o desenvolvimento da humanidade. A partir desses ensaios de Mário Moutinho e de toda uma produção de inúmeros autores no campo da museologia, que pensam a museologia não como uma técnica, mas como um sistema de conhecimento que aborda o Homem e sua relação com o objeto, a partir de significados socialmente construídos e compartilhados, passíveis de conflitos e lutas de poder simbólico, é que se pode procurar delimitar a linha tênue entre a museologia social e a Sociomuseologia. É verdade que elas se nutrem mutuamente, interpenetram entre si e entrelaçam-se quase que numa simbiose, mas não se podem confundir.

A Sociomuseologia, configurada como uma área disciplinar, como sugere Moutinho, dá conta das questões que envolvem o campo da museologia social, como também reflete sobre a atuação dos museus de uma forma geral, isto é, podem ser objeto de estudo e reflexão da Sociomuseologia tanto as "museologias indisciplinadas", como as "museologias colonizadoras e colonizadas" (CHAGAS \& GOUVEIA, 2014) e suas respectivas práticas.

A museologia social, por sua vez, é uma prática museológica que tem como pressupostos uma museologia que desloca seu foco do objeto para o homem, considerando-o como sujeito produtor de suas referências culturais, e engajada nos 
problemas sociais, de uma forma integral, das comunidades a que serve o museu. Para a museologia social, nas funções básicas de um museu, como preservar, pesquisar e comunicar, que devem ser executadas de forma participativa, os sujeitos sociais são a preocupação primeira, bem como os problemas sociais, econômicos, políticos e ambientais enfrentados pelas comunidades, com vistas à luta e à busca por seu desenvolvimento sociocultural ${ }^{2}$. Isso representa o que os militantes da museologia social chamam a "função social" dos museus. Nesse sentido, reportando-se a Hugues de Varine, Waldisa Rússio reforça que "mais do que existirem para os objetos, os museus devem existir para as pessoas" (GUARNIERI, 2010, p. 145).

Myriam Sepúlveda, no texto supracitado, aponta diferentes trabalhos que poderiam estar no âmbito da Sociomuseologia, como o $O$ amor pela arte: os museus de arte europeus e seu público, de Pierre Bourdieu, em que, a partir de uma pesquisa de público, mostra que os museus e galerias de arte não estão abertos para o público em geral, mas para um público específico que detém maior capital simbólico (no caso, expertise sobre obras de arte) e melhor se posiciona na hierarquia social. Os estudos de Mario Chagas (2009) também são citados por Sepúlveda, como A imaginação museal: museu, memória e poder em Gustavo Barroso, Gilberto Freyre e Darcy Ribeiro, em que faz uma análise do poder e do pensamento desses três pensadores, consagrados nas Ciências Sociais, na criação e na construção das narrativas do Museu Histórico Nacional, Museu do Homem do Nordeste e Museu do Índio, respectivamente.

Além desses, poderíamos citar as próprias reflexões de Myriam Sepúlveda, como seu trabalho $A$ escrita do passado em museus históricos (2006), que apresenta um olhar sociológico

\footnotetext{
2 Neste artigo, portanto, a partir deste momento, faço a distinção entre museologia social e Sociomuseoleogia, como ora proposto.
} 
sobre as coleções do Museu Histórico Nacional e do Museu Imperial, ao descrever os processos históricos e sociais de sua formação. Sem entrar em detalhes, poderíamos citar, ainda, os escritos e reflexões de José Reginaldo Santos Gonçalves (2003; 2007a; 2007b), Maria Célia Santos (2008), Nestor Canclini (1997, 1999), Francisco Régis Lopes Ramos (2008), entre tantos outros.

Cumpre acrescentar que Waldisa Rússio (2010) também entra nessa lista. Ela, inclusive, em inúmeros de seus textos, desde os anos 1970, reforçava que a Museologia é a ciência do Museu e das suas relações com a sociedade e que o objeto da Museologia é o fato museal ou fato museológico, entendido este como a relação profunda entre o homem e o objeto, parte da realidade sobre a qual o homem igualmente atua e pode agir. Em seus textos, não faz referências claras a $E$. Durkheim, mas ao considerar o fato museal como o objeto da Museologia, percebe-se que nessa ideia estão refletidos os preceitos do sociólogo francês, que leva em consideração os estudos dos fatos sociais no âmbito da Sociologia. Os fatos sociais, para Durkheim (2007), que não se podem confundir com fenômenos meramente orgânicos, consistem em maneiras de agir, de pensar e de sentir exteriores ao indivíduo. Essas maneiras são dotadas de um poder de coerção em virtude do qual esses fatos se impõem ao indivíduo. Waldisa Rússio, ao defender que a Museologia é a ciência do fato museológico, ressalva que não musealizamos todos os testemunhos do homem e do seu meio, mas somente aqueles traços ou vestígios carregados de significação. Essa relação do homem com o seu meio se dá de forma consciente, em termos de consciência crítica e histórica, ou seja, "o homem é o ser que se realiza criticamente, historicamente; ao realizar-se, ele constrói sua história e faz sua cultura" (GUARNIEIR, 2010, p. 150).

Não causaria estranheza, portanto, se o título do artigo de Myrian Sepúlveda fosse intitulado "Por uma Sociomuseologia". Mas cabe ainda entrar em detalhes de como 
surgiu e o que permeia essa onda da museologia social e do que vem a ser chamado de Nova Museologia, cujo expoente é o Movimento Internacional para uma Nova Museologia - Minom. É necessário compreender quais suas contribuições para as reflexões no âmbito da Sociomuseologia ou, nas palavras de Chagas e Gouveia (2014, p. 17), como esse novo pensamento encarou a tarefa de "escovar a museologia a contrapelo", que serviu de referência para a criação de diversos museus comunitários, chegando a influenciar, inclusive, diretrizes de políticas públicas para os museus mundo a fora.

\section{A herança de Santiago do Chile e o Movimento Internacional para uma Nova Museologia}

Em meio às influências das lutas e movimentos sociais que ocorreram em várias partes do mundo no segundo pós-guerra e as ideias revolucionárias nos anos 1960, uma nova postura do fazer museológico surgia, cuja principal preocupação são os sujeitos e os problemas sociais por que passam as comunidades a que o museu atende, com vistas à busca de seu desenvolvimento sociocultural. Essa prática, que ao longo do processo obtém distintos nomes e que aqui chamo de museologia social, tem como principais referências a MesaRedonda de Santiago do Chile e o Monvimento Internacional para uma Nova Museologia - Minom, cujos debates e pensamentos ecoaram em diversos países, como Canadá, França, Portugal e, sobretudo, na América Latina.

Georgina DeCarli (2003) explica que a relação entre museus e comunidades já vem de longa data na América Latina, embora nem sempre exitosa e muitas vezes marcada por conflitos e entraves. Essa relação, porém, encontrou nessa região a maior força, convicção e permanência no interesse dos museus em propiciar a participação da comunidade e é onde mais foram colocadas em prática propostas concretas nesse sentido. O seu relato, bastante contextualizado, traz, sobretudo, exemplos 
ocorridos no México durante os anos 1980 e 1990, a partir das iniciativas empreendidas pelo Instituto Nacional de Antropologia e História daquele país para a criação de museus comunitários. Também aborda a efervescência dessa prática em outros países e os diversos encontros e documentos internacionais que respaldam as ideias da chamada Nova Museologia.

O Movimento Internacional para uma Nova Museologia - Minom, explica DeCarli, teve sua origem "oficial" em dois importantes encontros internacionais. $\mathrm{O}$ primeiro deles foi a IX Conferência Internacional do Conselho Internacional de Museus - Icom, que aconteceu em Grenoble, na França, em 1971, onde foi gestado o conceito de "ecomuseu". Mas é na Mesa-Redonda de Santiago do Chile, intitulada "A importância e o desenvolvimento dos museus no mundo contemporâneo", promovida pela Organização das Nações Unidas para a Educação, a Ciência e a Cultura - Unesco, no ano seguinte, que o Minom tem maior expressão e cujas premissas são retomadas até hoje. Nessa Mesa-Redonda, os participantes delinearam as premissas de um "museu integral", de modo a responder às condições econômicas, culturais, sociais e políticas da América Latina. Ela se tornou, entre muitos profissionais dos museus da América Latina, símbolo da ruptura de uma museologia tradicional, centrada no objeto e que seguia um modelo de museu e de musealização tipicamente europeus. Em suas lembranças sobre esse encontro, o francês Hugues de Varine (2010), um de seus organizadores, ressalta a preocupação em "descolonizar" a realização desse evento, que tinha como finalidade pensar sobre o papel dos museus latino-americanos frente às transformações sociais por que passava a região, onde a língua de comunicação seria o espanhol e os especialistas convidados para palestra e coordenação das discussões seriam todos da América Latina.

Ecomuseu, museu integral, museu comunitário, museu de bairro, museu de vizinhança, museu de território, museu regional, entre outros foram termos e conceitos que 
passaram a fazer parte do vocabulário, das práticas museais e dos debates teóricos no campo da Museologia. Ressalte-se que o termo "ecomuseu", cunhado por Hugues de Varine, sofreu alterações em sua conceituação ao longo do tempo e a ele se atrelaram tantos outros adjetivos. Vale tomar como base a conceituação descrita por Brulon (2014) para o que se entende por ecomuseu na atualidade, após a dinâmica e evolução de sua ressignificação:

Como um novo conceito de museu, maleável, evolutivo por definição, e baseado em um modo de organização original no qual os poderes locais e os organismos de Estado são associados, o ecomuseu é previsto como um meio pelo qual as populações podem se tornar, elas mesmas, objetos de sua investigação - ele é, portanto, um instrumento de autoconhecimento, no qual uma performance do grupo produz conhecimento sobre o próprio grupo. (BRULON, 2014, p. 31).

Retomando os preceitos da Mesa-Redonda de Santiago do Chile, em 1984, resultante do I Atelier Internacional de Ecomuseus/Nova Museologia, foram publicados os princípios de base de uma Nova Museologia, documento conhecido como "Declaração de Quebec". Esse documento reforça a função social do museu e prega que

Ao mesmo tempo que preserva os frutos materiais das civilizações passadas, e que protege aqueles que testemunham as aspirações e a tecnologia actual, a nova museologia - ecomuseologia, museologia comunitária e todas as outras formas de museologia activa - interessa-se em primeiro lugar pelo desenvolvimento das populações, reflectindo os princípios motores da sua evolução ao mesmo tempo que as associa aos projectos do futuro. (DECLARAÇÃO DE QUEBEC, 1999, p. 223) 
Chagas e Gouveia (2014) advertem que a primeira década que se segue à Declaração de Quebec foi marcada por acirrada disputa entre os apoiadores da Nova Museologia e os defensores da chamada "museologia tradicional ou ortodoxa", bem como que a museologia social consolidou-se no Brasil mesmo à revelia de críticas e de posturas acadêmicas que não reconhecem seus avanços. Mesmo na atualidade, essa disputa ainda segue pautando as reflexões sobre o fazer museológico e os caminhos que seguiram a Nova Museologia e sua linha de pensamento. Sob este prisma, Tereza Scheiner (2012) procura desmitificar a Mesa-Redonda de Santiago do Chile, em vista de que alguns profissionais imputam-lhe significados inexistentes no texto da Carta resultante desse encontro, minimizando seu real significado e sua importância para o campo da Museologia. Defende que na área já existiam matrizes específicas de pensamento que fundamentam os conceitos de 'museu integral', 'museu de território', 'museu comunitário' e 'ecomuseu', bem como que as propostas e realizações de uma prática museológica voltada para o social não são originárias - e nem exclusivas - da Declaração de Santiago do Chile nem do Movimento Internacional para uma Nova Museologia - Minom. Em suas palavras:

A partir de Santiago, acreditou-se que o Museu Integral $^{3}$ seria aquele essencialmente voltado para a

\footnotetext{
${ }^{3}$ Segundo Hugues de Varine (apud DUARTE, 2013), o museu integral é aquele que leva em consideração a totalidade dos problemas da comunidade a que pertence, desempenhando um papel central como instrumento de uma animação participativa e de um desenvolvimento sustentável. Na acepção de Scheinner (2014), o museu integral se fundamenta na musealização de todo o conjunto patrimonial de um dado território e na ênfase no trabalho comunitário, bem como na capacidade intrínseca que possui qualquer museu de estabelecer relações com o espaço, tempo e memória, atuando junto a determinados grupos sociais. Shceinner sustenta que, a partir da Mesa de Santiago do Chile, acreditou-se que o museu integral seria aquele voltado
} 
ação comunitária - e, de certa forma, esqueceu-se que qualquer museu fundamenta-se numa nítida proposta social: a de aproximar o indivíduo dos processos e produtos da natureza e da cultura. (SCHEINNER, 2012, p. 19)

Nessa mesma linha de pensamento, Glauber Lima (2014) é bastante contundente e procura descortinar as reais intenções do que se convencionou chamar "Nova Museologia". Para o autor, essa corrente de pensamento está atrelada a um projeto que, na verdade, não representa um potencial de transformação da ordem social em uma perspectiva libertadora, emancipatória e desalienante, levando em consideração esses conceitos freirianos. $\mathrm{O}$ que realmente acontece é a manutenção e sofisticação da ordem vigente, que se constrói sobre forte influência liberal. Em sua crítica ferrenha, argumenta, ainda, que os discursos e estratégias da Nova Museologia apropriam-se de conceitos, ideias e proposições progressistas, ressignificando-os, mas que, na prática, ganham um sentido instrumental e despolitizante. Nessa ressignificação está a Pedagogia Libertadora, de Paulo Freire, sob forte inspiração marxista, que é um dos pilares dos preceitos da Nova Museologia e basilar no pensamento e ação de Hugues de Varine, também um dos precursores e defensores dessa corrente museológica, como ele mesmo faz questão de explicitar (VARINE, 2014).

É bastante provável que a ideia de museu integral e da afirmação do papel social do museu, como importante instituição para o desenvolvimento sociocultural da região onde está inserido, não tenha realmente origem na Mesa-Redonda de Santiago do Chile, como defende Shceinner. Certamente, o teor das Resoluções dessa Mesa-Redonda é resultado de um processo de discussões e reflexões teóricas no campo da museologia como

essencialmente para a ação comunitária, mas entende que todo e qualquer museu fundamenta-se numa nítida proposta social. 
as descritas por Myriam Sepúlveda (2014). É também reflexo de lutas sociais anteriores que influenciaram e impactaram nas decisões ali tomadas. Entretanto, não podemos generalizar que "qualquer museu fundamenta-se numa nítida proposta social" (SHCEINNER, 2014). Afirmar isso é esquecer que o campo dos museus é também um campo de conflitos e de disputas, em que, a todo momento, travam-se relações de poder nesse jogo social e que muitos museus fundamentam-se, isso sim, numa nítida proposta opressora, colonizadora e despolitizante.

A contundente fala de Glauber Lima também reflete os conflitos que existem dentro do próprio pensamento museológico. Ela é importante para se observar até que ponto práticas museológicas que advogam os preceitos de uma museologia social utilizam-se de discursos progressistas para, na verdade, seguirem uma prática museológica homogeneizante e colonizadora, que propicia uma legitimação dada, não instigando uma reflexão crítica sobre essa legitimação e à ideologia subjacente a esse status quo, contribuindo para a sua manutenção e reprodução. Mas não se pode negar que a onda de pensamento no campo dos museus surgida a partir da segunda metade do século XX, convencionalmente chamada por muitos de Nova Museologia, com pressupostos em uma museologia social, desconcertou o fazer museal. Seus fundamentos e concepções se tornaram alvo de questionamentos e reflexões, tanto na praxis museológica, no seu dia a dia, como dentro dos campos de estudo das Ciências Sociais, sendo o próprio museu e suas práticas representacionais objeto de análise. Um novo olhar e um novo fazer museal, bastante ramificado na América Latina como aponta DeCarli, libertaram os museus do pensamento europeu, dos museus tradicionais de arte e de história. São as raízes de um museu libertado e libertador: libertação da dependência colonial, dos modelos impostos, da classificação acadêmica e dos modelos da alta cultura. São raízes de um museu voltado para as "memórias 
subterrâneas" (POLLAK, 1989) e engajado na luta contra os abusos da memória e do esquecimento, na perspectiva de Paul Ricouer (2007).

Chagas et all (2014), ao refletirem sobre a Declaração do Minom Rio 2013, documento resultante da XV Conferência Internacional do Minom, em agosto de 2013, no Rio de Janeiro, demonstram que essa declaração reforça os pressupostos de empoderamento dos diferentes seres e agentes portadores de memória, indicando a necessidade de "quebrar hierarquias de poder, a fim de que surjam novos protagonistas de suas próprias memórias" (CHAGAS et all, 2014, p. 432). Esse documento reconhece que a "Museologia Social consiste num exercício político que pode ser assumido por qualquer museu, independente de sua tipologia" (CHAGAS et all, 2014, p. 435) e reflete, ainda, os ideiais freirianos, ao defender "a valorização dos estudos das memórias numa perspectiva libertadora e do respeito pela dignidade humana" (CHAGAS et all, 2014, p. 436).

As premissas da Mesa-Redonda de Santiago do Chile de 1972 e de outros documentos que se seguiram, como a Declaração de Quebec de 1984 e a Declaração do Minom Rio 2013, são importantes porque colocam em evidência e em ebulição uma prática museológica que questiona o próprio fazer museológico. Isso não quer dizer que os museus ditos tradicionais não possam ou não assumem seu papel social de interface com os distintos sujeitos sociais e seus processos socioculturais. E até mesmo que todos os museus comunitários e congêneres assumem esse papel a contento.

Mas é fato que a prática museológica precisou ser colocada em xeque. O encontro de 1972 foi importante nesse sentido para aquele momento e para os anos subsequentes. Os ares da Mesa-Redonda de Santiago do Chile, a partir de então, ecoaram, tanto na criação de museus comunitários e na ressignificação das narrativas e práticas museológicas dos 
museus já existentes, como também nas reflexões teóricas na linha de pensamento da Sociomuseologia.

\section{Referências}

BRASIL. Ministério da Educação e Cultura. Departamento de Assuntos Culturais. Instituto Joaquim Nabuco de Pesquisas Sociais. (1976). Subsídios para implantação de uma política museológica brasileira. Recife: MEC/DAC/IJNPS.

BRULON, Bruno. (2014). Os mitos do ecomuseu: entre a representação e a realidade dos museus comunitários. In Musas - Revista Brasileira de Museus e Museologia, no 6. Brasília: Instituto Brasileiro de Museus, 28-45.

CANCLINI, Nestor García. (1997). Culturas Híbirdas: estratégias para entrar e sair da modernidade. São Paulo: Editora da USP, 1997.

. (1999). Los usos sociales del patrimonio cultural. In AGUIAR CRIADO, Encarnación. Patrimonio etnológico: nuevas perspectivas de estúdio. Andaluzia: Consejeria de Cultura, 16-33. CHAGAS, Mario de Souza. (2006). Há uma gota de sangue em cada museu: a ótica museológica de Mário de Andrade. Chapecó: Argos.

. (2009). A imaginação museal: museu, memória e poder em Gustavo Barroso, Gilberto Freyre e Darcy Ribeiro. Rio de Janeiro: MinC/Ibram.

CHAGAS, Mario. GOUVEIA, Inês. (2014) Museologia social: reflexões e práticas (à guisa de apresentação). In Museologia Social. Cadernos do Ceom. Ano 27, no 41. Chapecó: Unochapecó, 9-22.

CHAGAS, Mario; ASSUNÇÃO, Paula; GLAS, Tamara. (2014). Museologia social em movimento. In Museologia Social. Cadernos do Ceom. Ano 27, no 41. Chapecó: Unochapecó, 429436.

DECARLI, Georgina. (2003). Vigencia de la Nueva Museología en América Latina: conceptos y modelos. In Revista ABRA de la 
Facultad de Ciencias Sociales de la Universidade Nacional. Costa Rica: Editorial EUNA, jul-dez.

DECLARAÇÃO DE QUEBEC. (1999). Princípios básico de uma Nova Museologia (1984). In Cadernos de Sociomuseologia, no 15. Lisboa: Universidade Lusófona de Humanidades e Tecnologia, 223-225.

DURKHEIM, E. (2007). As regras do método sociológico. São Paulo: Martins Fontes.

GONÇALVES, José Reginaldo Santos. (2003). O patrimônio como categoria de pensamento. In ABREU, Regina \& CHAGAS, Mário (orgs.). Memória e patrimônio: ensaios contemporâneos. Rio de Janeiro: DP\&A, 21-29.

. (2007a). Os limites do patrimônio. In LIMA FILHO, Manuel Ferreira; ECKERT, Cornelia; BELTRÃO, Jane (orgs). Antropologia e patrimônio cultural: diálogos e desafios contemporâneos. Blumenau: Nova Letra, 239-248.

. (2007b). Antropologia dos objetos: coleções, museus e patrimônios. Rio de Janeiro: IPHAN.

GUARNIERI, Waldisa Rússio Camargo. (2010). Textos e contextos de uma trajetória profissional. Organização de Maria Cristina Bruno. Volume 1. São Paulo: Pinacoteca do Estado / Secretaria de Estado de Cultura / Comitê Brasileiro do Conselho Internacional de Museus.

LIMA, Glauber Guedes Ferreira de. (2014). Museus, desenvolvimento e emancipação: o paradoxo do discurso emancipatório e desenvolvimentista na (Nova) Museologia. In Revista Eletrônica do Programa de Pós-Graduação em Museologia e Patrimônio - Unirio/Mast. Vo. 7, no 02. Rio de Janeiro: Unirio/Mast, 85-106.

LONDRES, Cecília. (2005). O patrimônio em processo. Trajetória da política federal de preservação no Brasil. Rio de Janeiro: Editora UFRJ / MinC-Iphan. 
MOUTINHO, Mário C. (1993). Sobre o conceito de museologia social. In Cadernos de Sociomuseologia. Vol. 1, no 1. Lisboa: Universidade Lusófona de Humanidades e Tecnologia, 7-9. . (2014). Definição evolutiva de Sociomuseologia: proposta de reflexão. In Museologia Social. Cadernos do Ceom. Ano 27, no 41. Chapecó: Unochapecó, 423-427.

POLLAK, Michael. (1989). Memória, esquecimento, silêncio. In Estudos Históricos. Rio de Janeiro, vol. 2, n. 3, 3-15.

PRIMO, Judite. (1999). Museologia e Patrimônio: Documentos Fundamentais (org.). Cadernos de Sociomuseologia. Museologia e património: documentos fundamentais. Vol. 15, no 15. Lisboa: Universidade Lusófona de Humanidades e Tecnologia.

RAMOS, Francisco Régis Lopes. (2008). A danação do objeto: O museu no ensino de História. Chapecó: Argos.

RICOEUR, Paul. (2007). A memória, a história, o esquecimento. Campinas: Editora da Unicamp.

SANTOS, Myrian Sepúlveda dos. (2003). Memória coletiva e teoria social. São Paulo: Annablume.

. (2006). A escrita do passado em museus históricos. Rio de Janeiro: Garamond, MinC, Iphan, DEMU.

- (2014). Por uma sociologia dos Museus. In Museologia Social. Cadernos do Ceom. Ano 27, no 41. Chapecó: Unochapecó. 47-70.

SCHEINER, Tereza Cristina. (2012). Repensando o Museu Integral: do conceito às práticas. Boletim do Museu Paraense Emílio Goeldi. Ciências Humana, v. 7, n. 1, p. 15-30, jan-abr.

SILVA, Fernando Fernandes da. (2002). Mário e o patrimônio: um anteprojeto ainda atual. In Revista do Patrimônio, no 30. Brasília: Iphan, p. 128-137.

TOLENTINO, Átila B. (2011). Governança em rede: o caso do Sistema Brasileiro de Museus. In RENNÓ, Lucio (Org.). Coletânea de políticas públicas de cultura: práticas e reflexões. Brasília: Universidade Católica de Brasília/Ministério da Cultura. 179-225. 
VARINE, Hugues. (2010). A respeito da Mesa-Redonda de Santiago do Chile (1972). In BRUNO, Maria Cristina Oliveira (org.). Icom/Brasil e o pensamento museológico brasileiro: documentos selecionados. São Paulo: Pinacoteca do Estado / Secretaria de Estado da Cultura / Comitê Brasileiro do Conselho Internacional de Museus, 38-42.

. (2014). Entrevista de Hugues de Varine concedida a Mario Chagas. In Museologia Social. Cadernos do Ceom. Ano 27, no 41. Chapecó: Unochapecó: 239-248. 